\title{
Profile Scanning Measurements of Far-Field from Plastic Optical Fibre (POF) Passive Devices for Bandwidth Characterization in Datacom Networks
}

\author{
Ricardo M. Ribeiro, Vinicius N. H. Silva, Yanes C. Balod, Andres P. L. Barbero, Sydney B. Germano and \\ Paulo A. M. dos Santos
}

\begin{abstract}
This paper reports on the investigations of the beam profile scanning measurements using an image technique set-up. The records are made by means of CCD camera coupled to a computer frame grabber, used to capture the far-field profile from single POFs, and passive POF-devices as connectors and couplers. The free distributed ImageJ, an image analysis software, was used to pre-processing the acquired beam profile images. The known model of effective numerical aperture $\mathrm{NA}_{\text {eff }}$ is used to estimate the optical bandwidth. Comparisons among the far-field and bandwidths for POFs with and without passive devices are done.
\end{abstract}

Keywords - Datacom networks, plastic optical fibres, passive devices, CCD, bandwidth, effective numerical aperture.

Resumo - Este trabalho descreve investigações do campo distante de feixes luminosos por captura de imagem e análise por varredura radial. As medidas do campo-distante de POFs e dispositivos passivos, tais como conectores e acopladores, são feitas com o uso de uma câmera CCD acoplada a uma placa de captura de imagens inserida num computador. O software Image $J$ de uso livre, é utilizado na aquisição e pré-processamento das imagens. $O$ modelo da abertura numérica efetiva $\mathbf{N A}_{\text {eff }}$ é utilizado para estimar a banda-passante óptica. As medidas de campo-distante e banda-passante de fibras puras e incluindo dispositivos passivos são comparadas entre si.

Palavras-chaves - Redes de comunicação de dados, fibras ópticas plásticas, dispositivos passivos, CCD, banda-passante, abertura numérica efetiva.

\section{INTRODUCTION}

The most fabricated POF is the standard PMMA 1 mm-core diameter and 0.46-0.50 numerical aperture. This POF is cheap, easy of handle and mechanically resilient. [1]. It is commonly used in car networks, automations systems, sensors and illumination. However, the high-bandwidth of such fibres was already demonstrated allowing their application for optical links like Datacom, home-wiring [1] and FTTH access networks using a single wavelength channel up to $425 \mathrm{~m}$ length $[\mathbf{2 , 3}$. Furthermore, low-NA (NA =

Ricardo M. Ribeiro, rmr@pq.cnpq.br, Vinicius N. H. Silva, vinidelsilva@terra.com.br, Yanes C. Balod, yanes@pobox.com, Andres P. L. Barbero, pablo@telecom.uff.br, Sydney B. Germano, bragantine@gmail.com, Laboratório de Comunicações Ópticas, Departamento de Engenharia de Telecomunicações, Universidade Federal Fluminense, 24.210-240 Niterói RJ Brasil, Paulo A. M. dos Santos, pams@if.uff.br, Laboratório de Óptica Não Linear \& Aplicada, Instituto de Física, Universidade Federal Fluminense, Niterói RJ Brasil. The authors would like to thank MCT/CNPq and Faperj for the financial support of this research under grants 303102/2006-3 and E-26/171.158/2005 respectively.
0.30) PMMA POFs are also available allowing a bandwidth increase over three times. PMMA GI POFs of much higher bandwidth > $2 \mathrm{GHz} .100 \mathrm{~m}$ [1] have been developed and also reached the market.

The classical book written by D. Marcuse [4] describes fibre characterization techniques, most of them still in use today. The light beam profile scanning technique using CCD image sensors has been shown to be relatively simple. However, it is a powerful tool for POF transmission analysis [5-7]. Many POF parameters as bandwidth and mode coupling from farfield, and refractive index profile from near-field beam image measurement have been reported [6,8].

Couplers fabricated from single-mode silica fibres split or tap the power but not change the propagating mode quantity (1 mode). The input is usually one single-mode signal and the output should be at least two single-mode signals, both with reduced power. Therefore, mode conversion and bandwidth change are not expected to occur along single-mode fibre, traverse connectors, couplers and bends. However, this is not always true for multimode fibre systems, mainly for highly multimode $1 \mathrm{~mm}$-diameter POFs. 
Measurements of the light beam-profiling images from POF-couplers is not new, but only comparisons among the spot distances relative each other as a function of decoupling angle $\phi$ between the receiving POFs were done [9]. H. Yuuki et al.[10] reported the ultrasonic welding technique to manufacture star POFcouplers. They showed a cut-off frequency at $-3 \mathrm{~dB}$ response for an $8 \times 8$ star coupler, measuring it by the conventional time-domain method and gives $\mathrm{f}_{\mathrm{C}}=10.4$ GHz. Such paper also shows 8 spot images in the nearfield from each of the coupler arms. From the radial distribution of light intensity it was revealed that the mode content differs for each exit arms. This different radial distribution of light intensity produces a different $\mathrm{NA}_{\text {eff }}$, and indicates that a different bandwidth for each arms are expected.

In this paper we report results from experimental investigations using an image light beam-profiling technique set-up. The measurements are made by means of CCD camera of good sensitivity and resolution coupled to a computer frame grabber for the far-field record from systems accounting single POFs and POF-passive devices as connectors and couplers inserted on links. The free-distributed ImageJ, an image analysis software, was used to analyse the acquired beam profile images. The known model of effective numerical aperture $\mathrm{NA}_{\text {eff }}$ is used to estimate the bandwidth after the signal traverse a passive device or single POF length. Comparisons among the acquired results for single POFs with and without passive devices are done.

\section{THEORY}

Assuming Gaussian-shaped pulses, the analogue optical bandwidth $\mathrm{B}_{\text {opt }}$ of POFs may be approximately calculated from equation (1) where $\Delta \tau$ is the time broadening at $-3 \mathrm{~dB}$ of light pulses due to one or more dispersive mechanisms [1].

$$
\mathrm{B}_{\mathrm{opt}} \approx \frac{0.44}{\Delta \tau}
$$

From (1) and using a known geometrical approach [1], the bandwidth of a SI POF due modal dispersion alone, but without mode-coupling, may be calculated from (2).

$$
B_{\bmod a l}^{M M-S I}=\frac{0.88 n_{1} c}{(\mathrm{NA})^{2}} \frac{1}{\mathrm{~L}}
$$

In (2), $\mathrm{n}_{1}, \mathrm{c}, \mathrm{L}$ and NA are the core refractive index, vacuum light velocity, fibre length and nominal numerical aperture, respectively. The later is given by (3) valid only for meridional rays where $n_{2}$ is the cladding refractive index.

$$
\mathrm{NA}=\sqrt{\mathrm{n}_{1}^{2}-\mathrm{n}_{2}^{2}}
$$

The bandwidth of POFs is mainly limited due modal dispersion and it is a subtle issue because large core fibres can carry millions of modes. When enough fibre length or in-line mode-scrambles [1] are used, the bandwidth becomes higher than those calculated from the nominal numerical aperture NA, i.e. from (2) and (3). The mode-coupling tends to average out the total propagation delay, thus reducing the modal dispersion. Depending on the launch condition, the bandwidth may increase more than ten times [11]. Moreover, the model of effective numerical aperture $\mathrm{NA}_{\mathrm{eff}}$ is useful to estimate the bandwidth $\mathrm{x}$ length after the signal to traverse a POF length, connector, coupler or bends (mode-scramblers) by using $(4)[\mathbf{1 , 1 2}]$.

$$
(\mathrm{BL})_{\mathrm{mod} \mathrm{al}}^{\mathrm{MM}-\mathrm{SI}}=\frac{0.88 \mathrm{n}_{1} \mathrm{c}}{\left(\mathrm{NA}_{\mathrm{eff}}\right)^{2}}
$$

The bandwidth values indirectly measured by means of the far-field numerical aperture $\left(\mathrm{NA}_{\mathrm{eff}}\right)$ correlate very well with bandwidth measurement made by pulse propagation [1]. After reaching the equilibrium mode distribution (EMD) condition, the bandwidth would change without affecting the far-field [11].

\section{EXPERIMENTAL}

The experimental set-up is a classic configuration similar of those reported [13] and is schematically shown at Figure 1. HeNe laser emitting collimated beam at $633 \mathrm{~nm}$ is used as light source. It was launched into the POF with an adjustable $\alpha$ angle. The light propagates along the standard PMMA SI POFs (NA = 0.47) Eska Extra EH 4001 of Mitsubishi Rayon (Japan) and may traverse passive devices as connectors and couplers. The connector could be index matched using an oil of $\sim 1.49$ refractive index. The far-field is displayed onto a screen. A CCD-camera Jyn Chyau Company model JCC-510 NTSC with CCD sensor $1 / 3^{\prime}, 512(\mathrm{H}) \times 492(\mathrm{~V})$ pixels, $\mathrm{S} / \mathrm{N}>46 \mathrm{~dB}, \mathrm{C}$-mount with zoom objective $2.828 / 50 \mathrm{~mm}$. Such camera with a frame grabber acquires the images in reflective configuration. 


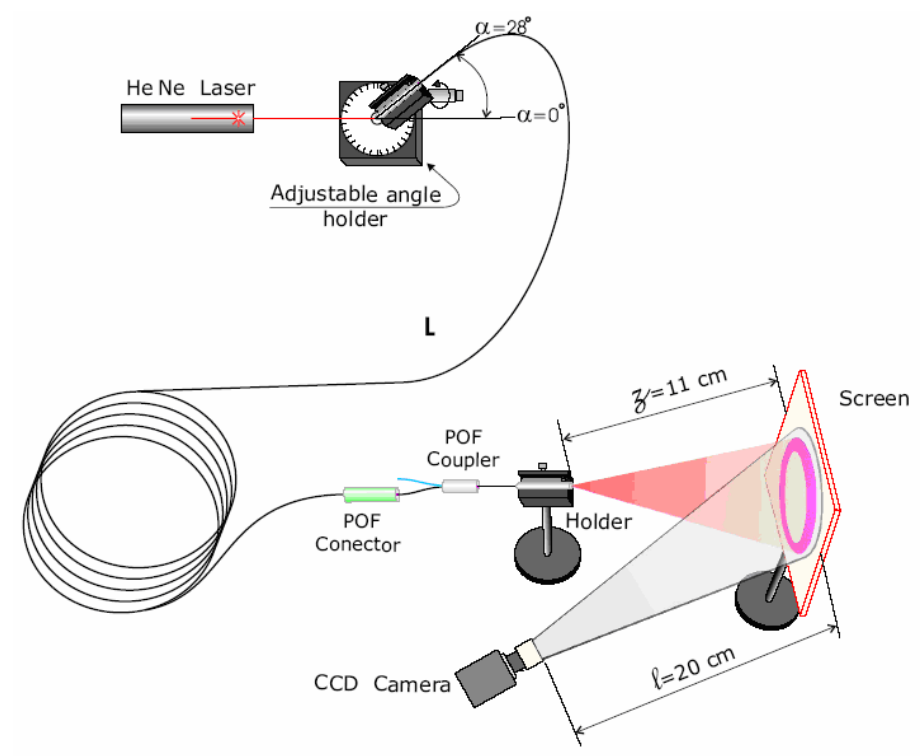

Fig. 1. The experimental set-up comprising a connector and coupler inserted in the link.

\section{RESULTS AND DISCUSSIONS}

By fitting a Gaussian shaped radial profile for the farfield, the pattern width $\mathrm{W}_{5 \%}$ at $5 \%$ intensity maximum is extracted. This is the standard procedure to compute $\mathrm{NA}_{\text {eff }}$ [1]. Thus, the $\mathrm{NA}_{\text {eff }}$ may be easily calculated using simple geometry and the definition $\mathrm{NA}_{\text {eff }} \equiv$ $\mathrm{n}_{0} \operatorname{sen} \theta_{\text {eff }}$ where $\mathrm{n}_{0}=1$ is the refractive index of air. By using (2) and the manufacturer data-sheet, the

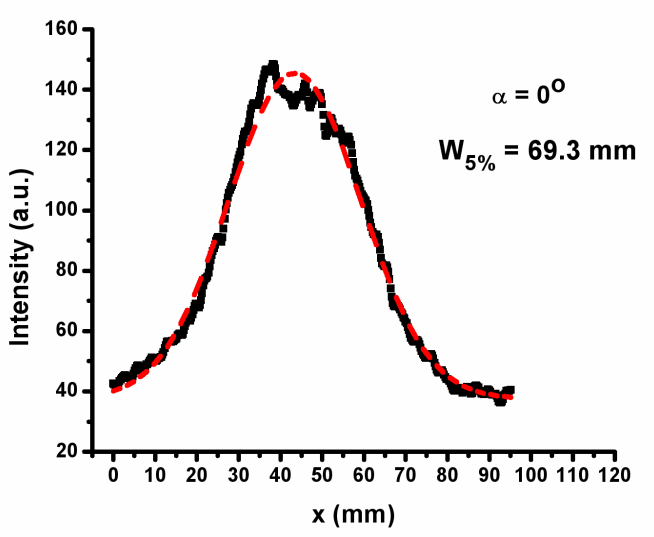

(a) bandwidth $\mathrm{x}$ length is calculated as $(\mathrm{BL})_{\mathrm{mod} a \mathrm{al}}^{\mathrm{MM}-\mathrm{SI}}=1.78$ MHz.km.

Figures 2 show the plots of the far-field pattern from short $(\sim 1 \mathrm{~m})$ and long $(\sim 19 \mathrm{~m})$ POF lengths. Using an adjustable angle holder (see Figure 1), the light was launched at $\alpha=0^{\circ}$ angle.

Fig. 2. Plot of the far-field pattern from (a) short ( 1m) and (b) long ( 19m) POF lengths. The light was launched at $\alpha=0^{\circ}$ angle. The EMD is not reached yet.

Measurements gives $\mathrm{NA}_{\text {eff }}(\mathrm{L}=1 \mathrm{~m})=0.30$ and $\mathrm{NA}_{\text {eff }}(\mathrm{L}=19 \mathrm{~m})=0.34$, but as can be seen at Figure 5 $\left(\alpha=20^{\circ}\right)$, the EMD regime is not reached yet. This is because the far-field profile depends on launch angle. In addition, Figure $2 \mathrm{~b}$ shows an asymmetric pattern due non-equalized effect of bents along POF propagation
[14]. As $L$ is increased, the $B_{\text {modal }} x \mathrm{~L}$ decreased from 4.37 MHz.km $(\mathrm{L}=1 \mathrm{~m})$ to $3.40 \mathrm{MHz} . \mathrm{km}(\mathrm{L}=19 \mathrm{~m})$.

Figures 3 shows the plots of the far-field pattern from long $(\sim 19 \mathrm{~m})$ POF length. The light was launched at $\alpha=$ $0^{\circ}$ angle for both links including a connector without (dry) and with (wet) refractive index matching oil. The 
connector joins $\mathrm{L}=19 \mathrm{~m}$ with a short piece $(\sim 33 \mathrm{~cm})$ of POF.

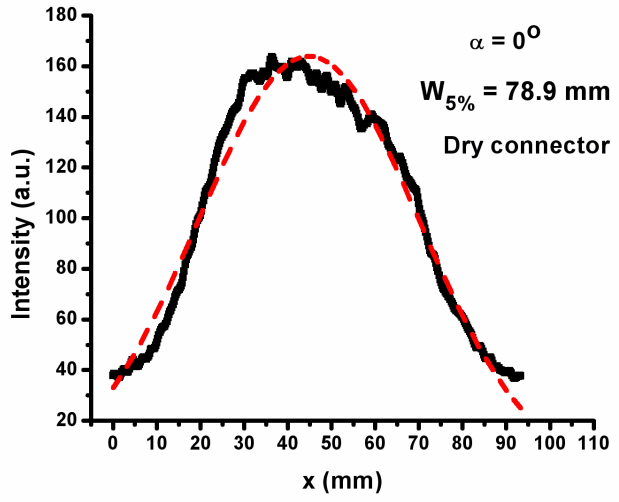

(a)

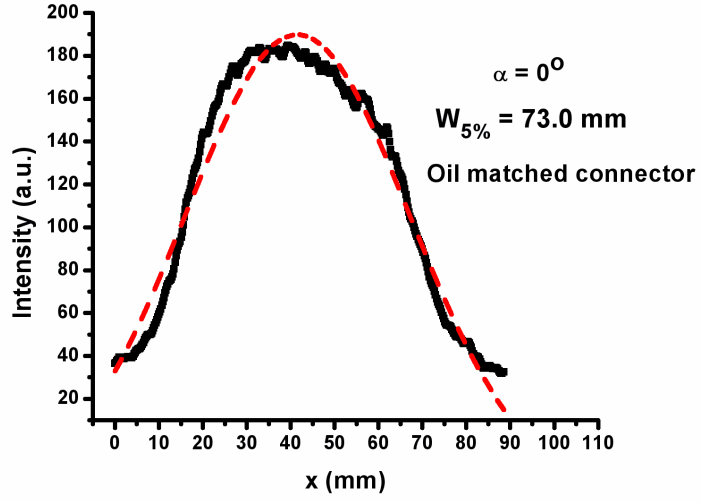

(b)

Fig. 3. Plot of the far-field pattern from long ( 19m) POF length. The light was launched at $\alpha=0^{\circ}$ angle for both links including a connector (a) without and (b) with the use of refractive index matching oil.

By comparing Figure 3a (dry connector) with Figure $2 \mathrm{~b}$ (without connector), almost none $\mathrm{NA}_{\text {eff }}$ and bandwidth change are observed. However, Figure $3 \mathrm{~b}$ shows that when the connector is index matched, the $\mathrm{NA}_{\text {eff }}$ drops to $\sim 0.31$ and the $\mathrm{B}_{\text {modal }} \mathrm{x} \mathrm{L}$ increases from 3.40 to 4.09 MHZ.km $(+16.7 \%)$. This is an unexpected result.

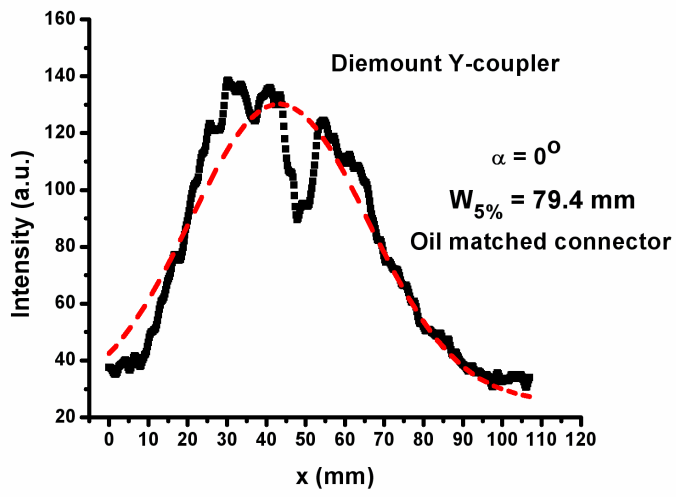

(a)
Figures 4 show the plots of the far-field pattern from two Y-type POF-couplers both light-feed with a long $(\sim 19 \mathrm{~m})$ POF length (see Figure 1). The light was launched at $\alpha=0^{\circ}$ angle for both links including an index matched connector. The tested Y-couplers were the commercially available Diemount00182 from Diemount and LIP101ES7 from Microparts.

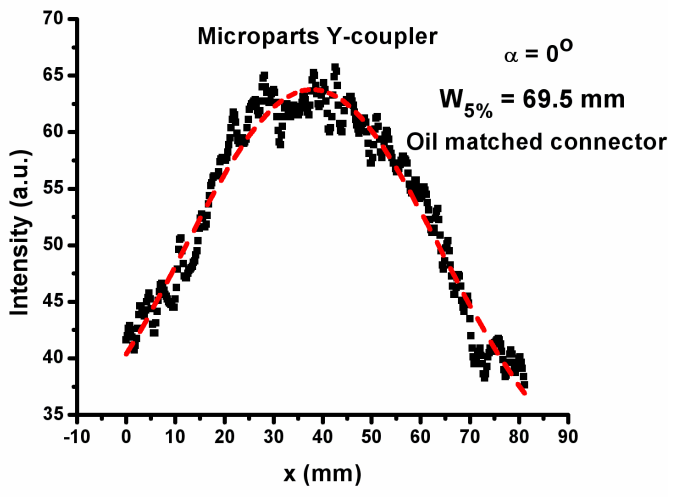

(b)

Fig. 4. Plots of the far-field pattern from two Y-couplers (a) Diemount 00182 and (b) Microparts LIP101ES7 both light-feed with a long $(\sim 19 \mathrm{~m})$ POF length. The light was launched at $\alpha=0^{\circ}$ angle, including an index matched connector.

Measurements gives $\mathrm{NA}_{\mathrm{eff}}=0.34$ and $\mathrm{B}_{\text {modal }} \times \mathrm{L}=$ $3.40 \mathrm{MHz} . \mathrm{km}$ after the Diemount and $\mathrm{NA}_{\text {eff }}=0.30$ and $\mathrm{B}_{\text {modal }} \mathrm{x} \mathrm{L}=4.37 \mathrm{MHz} . \mathrm{km}$ after the Microparts Ycoupler, respectively. It should be observed that results are not the same and both differs from the case were none coupler is inserted (see Figure $3 b$ ).
Figure 5 shows the plots of the far-field pattern from long $(\sim 19 \mathrm{~m})$ POF length. The light was launched at $\alpha=$ $20^{\circ}$ angle and includes an index matched connector followed by a very short POF length $(\sim 33 \mathrm{~cm})$. A ringshaped beam profile is now observed. 


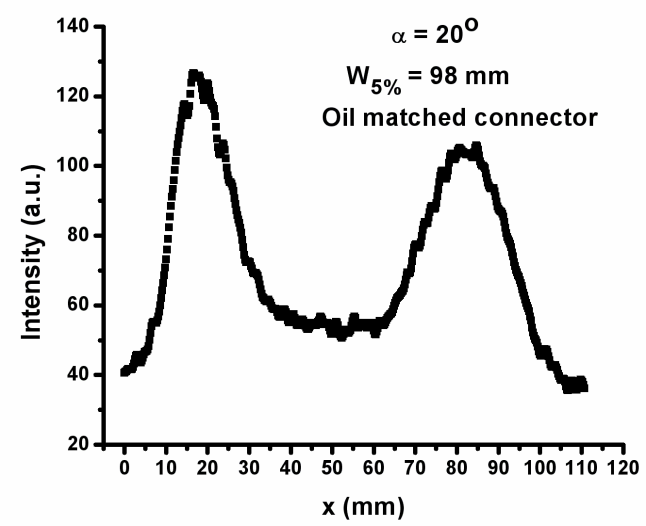

Fig. 5. Plot of the far-field pattern from long $(\sim 19 \mathrm{~m})$ POF length. The light was launched at $\alpha=20^{\circ}$ angle.

Although not presented here, when the connector is not index matched, the far-field pattern is a "blurred" ring-shaped beam profile. This is because for ringshaped pattern the dry connector promotes a stronger mode conversion than the index matched one. In order to guarantee "clean" results from measurements using Y-couples and also because the practical need to do connections, the later should be index matched to avoid appreciable mode conversion.

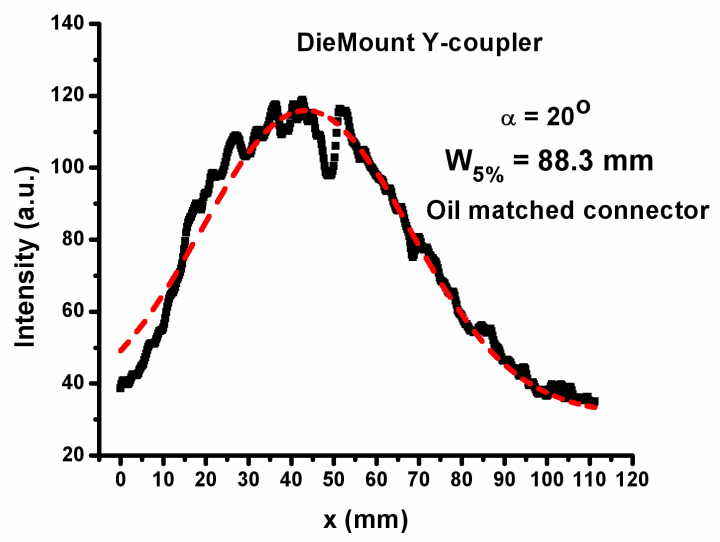

(a)

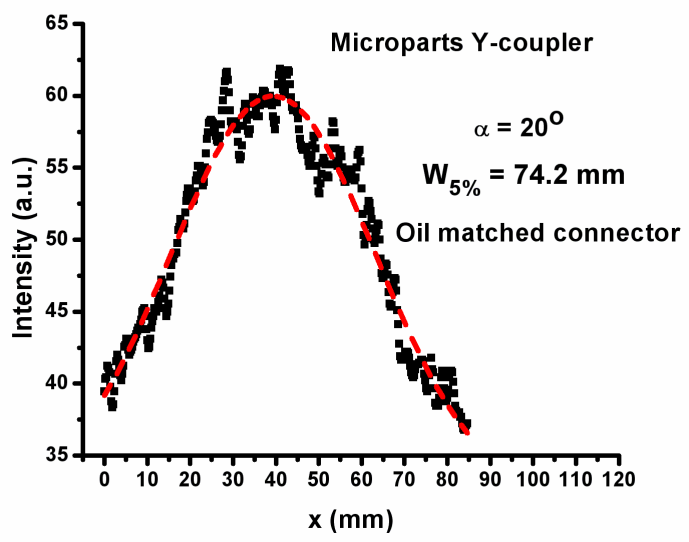

(b)

Fig. 6. Plots of the far-field pattern from Y-couplers (a) Diemount 00182 and (b) Microparts LIP101ES7 both light-feed with a long ( 19m) POF length. The light was launched at $\alpha=20^{\circ}$ angle, including an index matched connector.

Measurements gives $\mathrm{NA}_{\text {eff }}=0.37$ and $\mathrm{B}_{\text {modal }} \mathrm{x} \mathrm{L}=$ $2.87 \mathrm{MHz} . \mathrm{km}$ after the Diemount, and $\mathrm{NA}_{\text {eff }}=0.32$ and $\mathrm{B}_{\text {modal }} \mathrm{X} \mathrm{L}=3.84 \mathrm{MHz} . \mathrm{km}$ after the Microparts $\mathrm{Y}$ coupler, respectively. It should be observed that both results are once again not the same. The $\mathrm{NA}_{\text {eff }}$ and $\mathrm{B}_{\text {modal }} \mathrm{x} \mathrm{L}$ for the Microparts $\mathrm{Y}$-coupler is almost the same of the case where none Y-coupler is inserted (see Figure 3b).
As a crude estimative from $\mathrm{W}_{5 \%}=98 \mathrm{~mm}, \mathrm{NA}_{\text {eff }} \approx$ 0.41 and $\mathrm{B}_{\text {modal }} \mathrm{x} \mathrm{L}=2.34 \mathrm{MHz} \cdot \mathrm{km}$ are achieved. Therefore, high bandwidth degradation is observed because high-order modes are excited in the POF for $\alpha$ $=20^{\circ}$.

Figures 6 shows the plots of the far-field pattern from the Y-couplers both light-feed with a long $(\sim 19 \mathrm{~m}) \mathrm{POF}$ length (see Figure 1), but now launched at $\alpha=20^{\circ}$ angle. It includes an index matched connector.

\section{CONCLUSIONS}

The CCD-based beam profile imaging has been shown to be powerful and versatile technique. It relies on image measurement of near-field and far-field of light beam exiting POFs or POF-devices. Usually, by means of suitable image processing software, the technique is useful for many POF characterizations measurements as bandwidth, mode-coupling, fibre quality, refractive index profile, etc. It does not require 
the use of high-frequency equipments for bandwidth measurements.

This paper reported some experimental investigations on the influence (mode perturbations) of connectors and Y-couplers inserted in standards PMMA SI-POF links out of the EMD regime. Mode-conversion and bandwidth $\mathrm{x}$ length values changes are observed.

Dry connectors leads to a conversion and slightly filtering of modes. It does not appreciable change the bandwidth. Index-matched connectors provide filtering of modes at $\alpha=0^{\circ}$ angle thus increasing the bandwidth.

The insertion of Y-couplers may increase or decrease the bandwidth. It seems to depend on detailed fabrication process of such couplers. While the Diemount00182 is built from butt-coupling among POF ends [1], the Microparts is probably fabricated from side-polished POFs [15].

It is well known that connectors and couplers must be taken into account when a power budget of fibre links needs to be calculated. From results here presented, we believe that passive POF devices also influence the bandwidth (or rise-time) budget of highly multimode POF-systems. At least, the perturbations are significant for links out of the EMD where the optical receiver is not very far from the perturbing device.

\section{REFERENCES}

[1] W. Daum, J. Krauser, P.E. Zamzow and O. Ziemann, "POF Polymer Optical Fibers for Data Communication", Springer-Verlag (2002).

[2] Daniel Cárdenas, Roberto Gaudino, Antonino Nespola and Silvio Abrate, " $10 \mathrm{Mb} / \mathrm{s}$ Ethernet transmission over $425 \mathrm{~m}$ of large core step index POF", $15^{\text {th }}$ ICPOF, 46-50, Seoul, Korea (2006).

[3] M. Rizzeti, G. Bettoni and A. Nocivelli, "100 Mb/s Ethernet Transmission over $100 \mathrm{~m}$ of SI-PMMA Plastic Optical Fiber", $15^{\text {th }}$ ICOF, Seoul, Korea, 57-63 (2006).

[4] Dietrich Marcuse, "Principles of Optical Fiber Measurements", Academic Press, 1981.

[5] M. A. Losada, J. Mateo, D. Espinosa, I. Garcés and J. Zubia, "Characterization of the far field pattern for plastic optical fibres", $13^{\text {th }}$ ICPOF, 458-465, Nürnberg, Germany (2004).

[6] G. Aldabaldetreku, G. Durana, J. Zubia, J. Arrue, H. Poiseland ${ }^{\text {a }}$ A Losada, "Investigation and comparison of analytical, numerical, and experimentally measured coupling losses for multi-step index optical fibers", Optics Express, 13, 11, 4012-4036 (2005).

[7] J. Mateo, M. A., Losada and I. Garcés, " Global characterization of optical power propagation in step-index plastic optical fibers", Optics Express, 14, 20, 9028-9035 (2006).

[8] T. Ishigure, K. Ohdoko, Y. Ishiyama and Y. Koike, "Modecoupling control and new index profile of GI POF for restrictedlaunch condition in very-short-reach network", Journal of Lightwave Technology, 23, 12, 5155-4168 (2005).

[9] D. Kalymnios, "Plastic optical fibre tree couplers using simple Ycouplers", $1^{\text {st }}$ ICPOF, 115-118, Paris, France (1992).

[10] H. Yuuki, T. Ito and T. Sugimoto, "Plastic star coupler", Proceedings of SPIE, vol. 1592, 2-11 (1991).

[11] Douglas P. Karim, "Multimode dispersion in step-index polymer optical fibres", Proceedings of SPIE, vol. 1799, 57-66 (1992).

[12] D. Kalymnios, "Squeezing more bandwidth into high NA POF", $8^{\text {th }}$ ICPOF, 18-24, Chiba, Japan (1999).

[13] M. A Losada, I. Garcés, J. Mateo, I. Salinas and J. Zubia, "Mode coupling in plastic optical fibres of high and low numerical apertures", $10^{\text {th }}$ ICPOF, 109-112, Amsterdam, The Netherlands (2001).

[14] J. A. Arrue, G. Aldabaldetreku, G. Durana, J. Zubia, I. Garcés and F. Jimenéz, "Design of mode scrambler for step-index and graded-index plastic optical fibers", Journal of Lightwave Technology, 23, 3, 1253-1260 (2005).

[15] A. Weinert, "Plastic Optical Fiber: Principles, Components and Installation", Ed. Siemens, MCD Verlag, p. 115-116 (1999). 